\title{
A Comparative Study of Fuzzy Logic, Genetic Algorithm, and Gradient-Genetic Algorithm Optimization Methods for Solving the Unit Commitment Problem
}

\author{
Sahbi Marrouchi and Souad Ben Saber \\ The Laboratory of Technologies of Information and Communication and Electrical Engineering (LaTICE), \\ National Higher School of Engineers of Tunis (ENSIT), University of Tunis, 05 Avenue Taha Hussein-Monfleury, \\ 1008 Tunis, Tunisia
}

Correspondence should be addressed to Sahbi Marrouchi; sahbimarrouchi@yahoo.fr

Received 5 April 2014; Revised 19 June 2014; Accepted 20 June 2014; Published 16 July 2014

Academic Editor: Erik Cuevas

Copyright (C) 2014 S. Marrouchi and S. Ben Saber. This is an open access article distributed under the Creative Commons Attribution License, which permits unrestricted use, distribution, and reproduction in any medium, provided the original work is properly cited.

\begin{abstract}
Due to the continuous increase of the population and the perpetual progress of industry, the energy management presents nowadays a relevant topic that concerns researchers in electrical engineering. Indeed, in order to establish a good exploitation of the electrical grid, it is necessary to solve technical and economic problems. This can only be done through the resolution of the Unit Commitment Problem. Unit Commitment Problem allows optimizing the combination of the production units' states and determining their production planning, in order to satisfy the expected consumption with minimal cost during a specified period which varies usually from 24 hours to one week. However, each production unit has some constraints that make this problem complex, combinatorial, and nonlinear. This paper presents a comparative study between a strategy based on hybrid gradient-genetic algorithm method and two strategies based on metaheuristic methods, fuzzy logic, and genetic algorithm, in order to predict the combinations and the unit commitment scheduling of each production unit in one side and to minimize the total production cost in the other side. To test the performance of the optimization proposed strategies, strategies have been applied to the IEEE electrical network 14 busses and the obtained results are very promising.
\end{abstract}

\section{Introduction}

According to human activities, the electrical energy consumption is still increasing. Indeed, during one day the electricity demand is higher compared to the end of the night and this change is not related only to the day but also to the change of seasons, weekends, and so forth. In addition, the production of electricity must be compatible with the consumption considering the impossibility to store electricity. For this reason, the electric company must plan the operations of the production units and organize their moments of connection to the network and the duration of each operation. The unit commitment (UC) is the best solution in the field of modern power systems planning since the main objective is to schedule the production units to respond to the consumers demand with minimum cost. In fact, it allows both the optimization of the daily operational planning of electrical grids and the reduction of the total production cost through improving units while guaranteeing the continuity of service. The generation scheduling involves the determination of the commissioning and the quantity of power that should be generated by each unit during a specified planning period. Moreover, as each unit has its own production limits and its minimum start-up and shutdown times, it is the case of a complex, combinatorial, and nonlinear optimization problem [1]. Generally, the unit commitment problem depends directly on the unit production scheduling and on the economic dispatch, knowing that our system is subject to several constraints: power balance, spinning reserve, generation limits, and minimum start-up and shut-down times. Nevertheless, this problem concedes a multitude of problems such as the big size of the studied 
grid, the presence of coupling constraints, the presence of the operational constraints, and the time constraint which have to be low with respect to the size of the problem [2].

In this context, unit commitment scheduling has been established in order to make the best choice of production units that will be available to supply the forecasted load over a future period. Therefore, a study of the literature on methods, which focus on unit commitment (UC) problem resolution, shows that various numerical optimization techniques have examined this subject such as dynamic programming $[3,4]$, Lagrangian relaxation method [5-8], mixed integer programming [9], and branch-and-bound method [10-12]. It is worth mentioning that the dynamic programming method is simple but the calculation time required to converge to the optimal solution is quite long. Regarding the branchand-bound method, it adopts a linear function to represent the fuel and start-up costs during a time horizon. The disadvantage of this method is that the required execution time increases rapidly for UC problem having larger scales. The mixed integer programming uses linear programming to attain optimal solution. Nevertheless, this method was applied to small problems of unit commitment and they required major assumptions [9] that limit the margin of solutions. For the Lagrangian relaxation method, we note that the convergence time is an advantage, but the obtained solution is not ideal because of the complexity of the problem especially when the optimization problem contains a great number of production units.

In addition to the methods previously mentioned, there is another category of digital techniques applied to the UC problem. Specifically, there are the fuzzy logic $[13,14]$, the artificial neural network [15], the simulated annealing [16-18], the Tabu search [19], and the genetic algorithm [20-23]. These methods which can take into account more complex constraints are claimed to improve the quality of solutions. In this context, the works $[24,25]$ have presented a new strategy based on genetic algorithm to determine the priority order of the production units. The proposed strategy has presented an optimized unit commitment scheduling and the computation time taken through this strategy is promising. According to our study, we found that it is possible to use genetic algorithms to optimize the production cost while providing effective results. In fact, solving the unit commitment problem by genetic algorithm promotes the dynamic operation scheduling of each unit taking into account the system parameters, the operating constraints, and the requested load during a definite time horizon. We examined the works of Victoire and Jeyakumar [1] which consist of the integration of a hybrid optimization strategy to solve the unit commitment problem. This strategy is based on the combination of particle swarm optimization (PSO) method, the technique of sequential quadratic programming (SQP), and Tabu search (TS) method. The combinatorial part of the UC problem was solved using the TS method. Moreover, $[16,17,26]$ proposed a new technique using simulated annealing method. This technique increases the probability of generating feasible solutions and reduces significantly the time to research unfeasible solutions. With regard to [27], the adopted method is based on fuzzy logic approach to produce a logical and feasible solution for each horizon time and to take into account many uncertainties involved in the power systems planning. Indeed, the load demand and reserve margin are treated as fuzzy variables in order to estimate the required generated power in the electrical grid and to schedule this quantity among the production units considering the reserve margin and the power production limits.

We have proposed three strategies applied to IEEE electrical network 14 buses to solve the UCP in general and in particular to find the optimized combination scheduling of the produced power for each unit production. The first strategy is based on the use of fuzzy logic approach, the second one relies on the use of genetic algorithm, and the third strategy uses a hybrid optimization method, gradient-genetic algorithm. Throughout these three strategies, we arrived to develop an optimized scheduling plan of the generated power allowing a better exploitation of the production cost in order to bring the total operating cost to possible minimum when it is subjected to a series of constraints. A comparison was made to test the performances of the proposed strategies and to prove their effectiveness in solving unit commitment problems.

The paper is organized as follows; Section 2 is reserved to formulating the unit commitment problem. Next, in Section 3, methodologies of resolution through fuzzy logic, genetic algorithm, and gradient-genetic algorithm methods are presented. Section 4 deals with the discussion of simulation results and the main improvements of adopted strategies are highlighted. Finally, Section 5 resumes the main conclusions followed by references.

\section{Problem Formulation}

The objective of the UCP is the minimization of total production costs while determining the on/off states of each unit $U_{i h}$ over a period of time $H$. The problem is given according to the following function [28]:

$$
\begin{aligned}
\operatorname{Minimize} & {\left[F_{T}\left(P_{i h}, U_{i h}\right)\right.} \\
& \left.=\sum_{i=1}^{N_{g}} \sum_{h=1}^{H}\left[\phi_{i}\left(P_{i h}\right)+\mathrm{ST}_{i}\left(1-U_{i(h-1)}\right)\right] U_{i h}\right],
\end{aligned}
$$

where $\phi_{i}\left(P_{i h}\right)$ represents the polynomial function [29] defined by

$$
\phi_{i}\left(P_{i h}\right)=a_{i} P_{i h}^{2}+b_{i} P_{i h}+c_{i} .
$$

And $\mathrm{ST}_{i}$ represents the starting cost of the $i$ th unit defined by

$$
\mathrm{ST}_{i}= \begin{cases}\mathrm{HSC}_{i} & \text { if } \mathrm{MDT}_{i} \leq \tau_{i}^{\mathrm{OFF}} \leq \mathrm{MDT}_{i}+\mathrm{SC}_{i} \\ \mathrm{CSC}_{i} & \text { if } \tau_{i}^{\mathrm{OFF}}>\mathrm{MDT}_{i}+\mathrm{SC}_{i}\end{cases}
$$

where $a_{i}, b_{i}$, and $c_{i}$ : coefficients of the production cost, $P_{i h}$ : active power generated by the $i$ th unit $h$ th hour, $i=$ $1,2,3, \ldots, N_{g}$ and $h=1,2,3, \ldots, H, U_{i h}$ : on/off status of 
the $i$ th production unit at the $h$ th hour, $U_{i h}=0$ for the off state of one generating unit and $U_{i h}=1$ for the operating status of one generating unit, $\mathrm{HSC}_{i}$ : hot start-up cost of the $i$ th unit, $\mathrm{CSC}_{i}$ : cold start-up cost of the $i$ th unit, $\mathrm{MDT}_{i}$ : minimum down-time of the unit $i, \tau_{i}^{\mathrm{OFF}}$ : continuously off-time of unit $i$, $\mathrm{SC}_{i}$ : cold start time of unit $i, N_{g}$ : number of generating units, and $H$ : time horizon for UC (h).

Unit commitment is a highly constrained optimization problem. Different power systems have a different set of imposed constraints. The most common can be divided into two categories. The first, called unit constraints, represents the constraints that are applied to the single units; the second type, system constraints, contains those that are applied to the whole power system.

\subsection{System Constraints}

Power balance constraints: at any time over the planning horizon the total real power generation of the system must be equal to the total demand:

$$
\sum_{i=1}^{N_{g}} P_{i h} U_{i h}=P_{d h}
$$

Spinning reserve constraints: in order to prevent any abnormal operating conditions, the spinning reserve must be considered:

$$
P_{d h}+P_{r h}-\sum_{i=1}^{N_{g}} U_{i h} P_{i h} \leq 0 .
$$

\subsection{Unit Constraints}

Generation limits: these constraints require that the unit generation be within the minimal, $P_{i}^{\min }$, and maximal, $P_{i}^{\max }$, generation levels:

$$
P_{i}^{\min } \leq P_{i h} \leq P_{i}^{\max } .
$$

Minimum up-time constraint: the minimum up-time constraint determines the shortest duration a unit must stay in the generation mode, $\mathrm{MUP}_{i}$, after its transit to this mode:

$$
U_{i h}=1 \text { for } \sum_{t=h-\mathrm{up}_{i}}^{h-1} U_{i h} \leq \mathrm{MUT}_{i} .
$$

Minimum down-time constraint: The minimum down-time constraint specifies the shortest duration a unit must stay in the shut-down mode, $\mathrm{MDT}_{i}$, after it is shut down:

$$
U_{i h}=0 \text { for } \sum_{t=h-\text { down }_{i}}^{h-1} U_{i h} \leq \mathrm{MDT}_{i},
$$

with $P_{r h}$ : system spinning reserve at the $h$ th hour, $P_{d h}$ : amount of the consumed power at the $h$ th hour, $P_{i}^{\min }, P_{i}^{\max }$ : minimum and maximum power produced by a generator, $\mathrm{MUT}_{i}$ : continuously on-time of unit $i$, and $\mathrm{MDT}_{i}$ : continuously downtime of unit $i$.

The real practical barrier in the unit commitment problem is the high dimensionality of the possible search space. The mentioned unit and system constraints present the main limits of the search space of the studied model.

Here, in order to transform the complex nonlinear constrained problem into a linear unconstrained problem, we consider the following Lagrangian function:

$$
\begin{aligned}
L\left(P_{i h}, U_{i}, \lambda_{i}\right) & \\
= & \sum_{i=1}^{N_{g}} \sum_{h=1}^{H}\left[\phi_{i}\left(P_{i h}\right)+\mathrm{ST}_{i}\left(1-U_{i(h-1)}\right)\right] U_{i h} \\
& +\lambda_{i} \cdot\left(P_{d}-\sum_{i=1}^{N_{g}} P_{i} U_{i h}\right) .
\end{aligned}
$$

Herein, $\lambda_{i}$ is the Lagrangian coefficient.

The hypothesis tested in this paper is that the unit commitment dynamic can use both metaheuristic methods as hybrid methods to get the final commitment over the entire planning period.

\section{Methodology of Resolution}

For our case study, three optimization methods are used to solve the unit commitment problem; the first one uses the genetic algorithm. This strategy takes into account the advantage of the genetic algorithm speed in solving problems having a fairly complex architecture. The second method relies on the use of the fuzzy logic approach. The use of the fuzzy logic approach to solve this problem is depicted to the effectiveness of this optimization method in solving nonlinear difficult problems. Besides, the third strategy is based on the combination of two calculations methods, the genetic algorithm and the gradient method. The resolution of the unit commitment problem through gradient-genetic algorithm method is provided by a specific adjustment of the Lagrangian multipliers $\lambda_{i}$ of the Lagrangian function. The combined choice of these two methods is due to inquire about the rapidity of the genetic algorithm in the search for global minimum in first step and to operate the benefits the gradient method in a second step, since it is effective in terms of the quality of the obtained optimal solutions.

3.1. Genetic Algorithm. The fundamental principle of a genetic algorithm is to represent the natural evolution of organisms (individuals). In one individual's population, only the strongest, or in other words the best suited to the natural environment, survive and can give offspring $[16,20,25,27,30]$.

In each evolution stage, the genetic operators (selection, crossover, and mutation) operate based on the data structures in order to allow each individual to sweep the solutions horizon and to distinguish the global optimum among the local 
optima. At first, from an initial population of individuals, the evaluation function satisfies the following relation:

$$
\begin{aligned}
& F(U, P)=\frac{1}{1+K\left(\left(F_{\max } / F_{r}\right)-1\right)} \\
& \text { with } F_{r}=1 \times\left(\sum_{i=1}^{N_{g}} \sum_{h=1}^{H}\left[\phi_{i}\left(P_{i h}\right)+\mathrm{ST}_{i}\left(1-U_{i(h-1)}\right)\right] U_{i h}\right. \\
& \left.\qquad \lambda_{i} \cdot\left(P_{d}-\sum_{i=1}^{N_{g}} P_{i} U_{i h}\right)+\sum_{h=1}^{H} \beta_{h} \cdot L\right)^{-1},
\end{aligned}
$$

with $F_{\max }$ : maximum of the function $F_{r}$, L: penalty coefficient, $K$ : scaling coefficient, and $\beta_{h}$ : constant defined as follows:

$$
\begin{array}{ll}
\beta_{h}=1 & \text { if } C\left(P_{i h}, U_{i h}\right) \neq 0, \\
\beta_{h}=0 & \text { if } C\left(P_{i h}, U_{i h}\right)=0 .
\end{array}
$$

3.1.1. Selection. Genetic algorithm did not work on the real generator outputs themselves but on bit string encodings of them. The output of each one of the five generators is encoded in a 12-bit string, which gives a resolution of $2^{12}=4096$ discrete power values in the range $\left(P_{i}^{\min }, P_{i}^{\max }\right)$. For our case study, we have adopted the biased roulette wheel method in order to select the best chromosomes according to their performances obeying to the following equation:

$$
\operatorname{per} f\left(c_{i}\right)=\frac{f\left(c_{i}\right)}{\sum_{i=1}^{l} f\left(c_{i}\right)}
$$

where $l$ is the length of a binary string.

After the selection of the parent chromosomes, recombination and mutation take place to produce the offspring chromosomes. Owing to the nature of our coding and the use of integers, we cannot use the crossover and mutation operators in their classic form.

3.1.2. Crossover. Crossover is a structured, yet randomized, mechanism of exchanging information between strings. Crossover begins by selecting at random two members previously placed in the mating pool during reproduction. A crossover point is then selected at random, and information from one parent, up to the crossover point, is exchanged with the other parent. The probability of crossover $C_{r}$ is given by the following expression $[31,32]$ :

$$
C_{r}=K_{1} \cdot\left[\frac{\operatorname{Max}\left(1 /\left(1+K\left(\left(F_{\max } / F_{r}\right)-1\right)\right)\right)-F_{\mathrm{CROSS}}}{\operatorname{Max}\left(1 /\left(1+K\left(\left(F_{\max } / F_{r}\right)-1\right)\right)\right)-\bar{F}}\right] \text {, }
$$

where $F_{\text {CROSS }}$ is the larger of the fitness values of the solutions to be crossed, $\bar{F}$ is the average of the fitness function, and $K_{1}$ is the constant of proportionality.
3.1.3. Mutation. Mutation is generally considered a secondary operator. Mutation ensures that no string position will ever be fixed at a certain value for all the time. Mutation operates by toggling, in a binary code, any given string position with probability of mutation $M_{P}$. The expression of the probability of mutation is given as follows [31, 32]:

$$
\begin{aligned}
M_{P}=K_{2} \cdot[ & \operatorname{Max}\left(\frac{1}{1+K\left(\left(F_{\max } / F_{r}\right)-1\right)}\right) \\
& -\frac{1}{1+K\left(\left(F_{\max } / F_{r}\right)-1\right)} \\
& \left.\times\left(\operatorname{Max}\left(\frac{1}{1+K\left(\left(F_{\max } / F_{r}\right)-1\right)}\right)-\bar{F}\right)^{-1}\right],
\end{aligned}
$$

where $K_{2}$ is the constant of proportionality.

3.1.4. Convergence Criteria. GA terminates the evolution only when the generation reaches its maximum number. When convergence is obtained program finds all the possible on/off scheduling states $U_{i h}$ for the given load demand for 24 hours and displays the power $P_{i h}$ generated by each unit.

The process of solving the unit commitment problem by genetic algorithm method is performed according to Figure 1.

In passing from one generation to another, the old population should be replaced by the descendant's population newly created to maintain the search for better solutions. This step is important because it determines the degree of exploitation and advancement of the optimal solution search. This research is based on saving the best solution until the optimization progresses.

3.2. Fuzzy logic. Fuzzy logic provides not only a meaningful and powerful representation for measurement of uncertainties but also a meaningful representation of blurred concept expressed in normal language. Fuzzy logic is a mathematical theory, which encompasses the idea of vagueness when defining a concept or a meaning. For example, there is uncertainty or fuzziness in expressions like "low" or "high," since these expressions are imprecise and relative. Thus, the variables considered are termed "fuzzy" as opposed to "crisp." Fuzziness is simply one means of describing uncertainty.

Such ideas are readily applicable to the unit commitment problem. The application of fuzzy logic allows a qualitative description of the behavior of a certain system, the characteristics of the system, and its response without the need for exact mathematical formulation [13, 14, 33, 34].

To establish our strategy, we have considered the partial derivatives of the Lagrange function (9) with respect to each of the controllable variables equal to zero:

$$
\begin{aligned}
\frac{\partial L}{\partial P_{i h}} & =\frac{\partial\left[\phi_{i}\left(P_{i h}\right)\right]}{\partial P_{i h}}-\lambda\left(\frac{\partial P_{L h}}{\partial P_{i h}}-U_{i h}\right)=0, \\
\frac{\partial L}{\partial \lambda} & =P_{d h}-P_{L h}-\sum_{i=1}^{N_{g}} P_{i} U_{i h}=0 .
\end{aligned}
$$




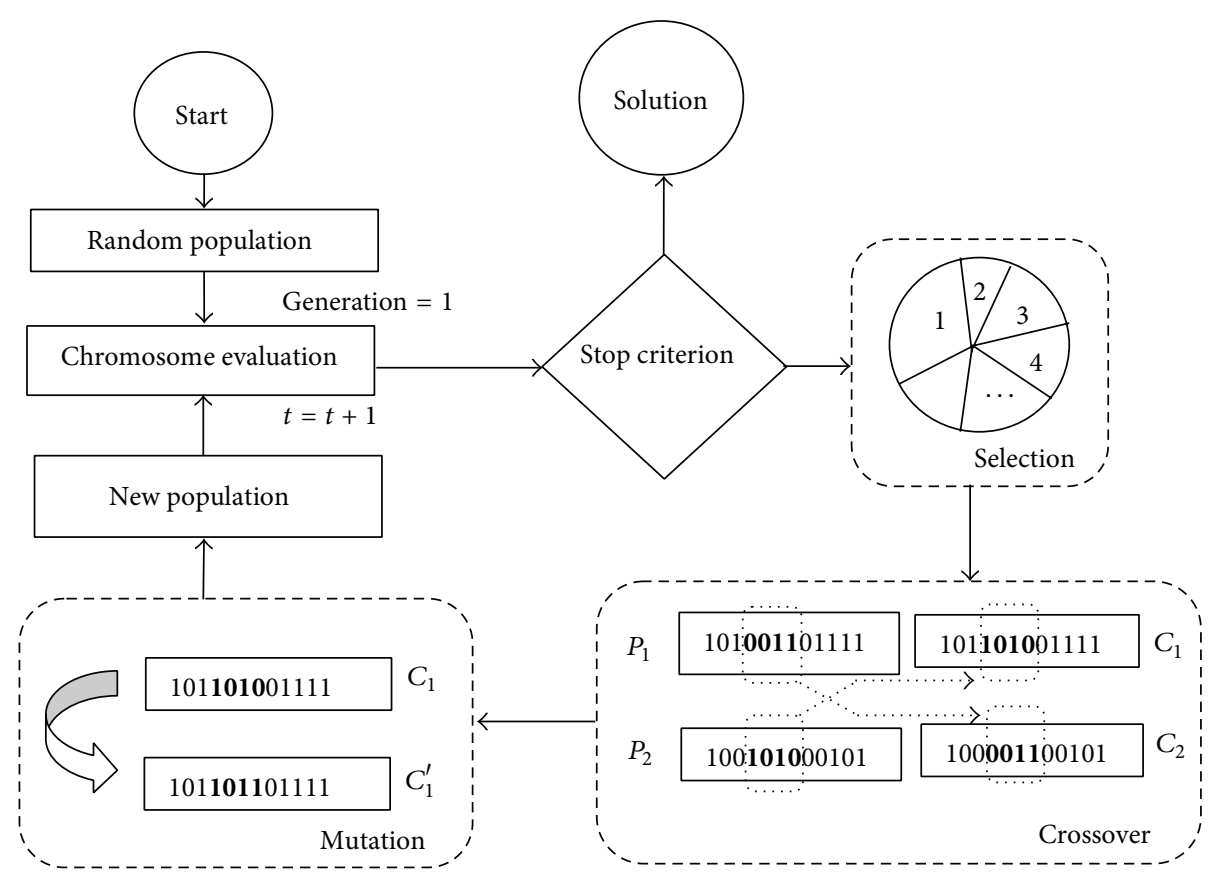

FIGURE 1: Operations of the genetic algorithm.
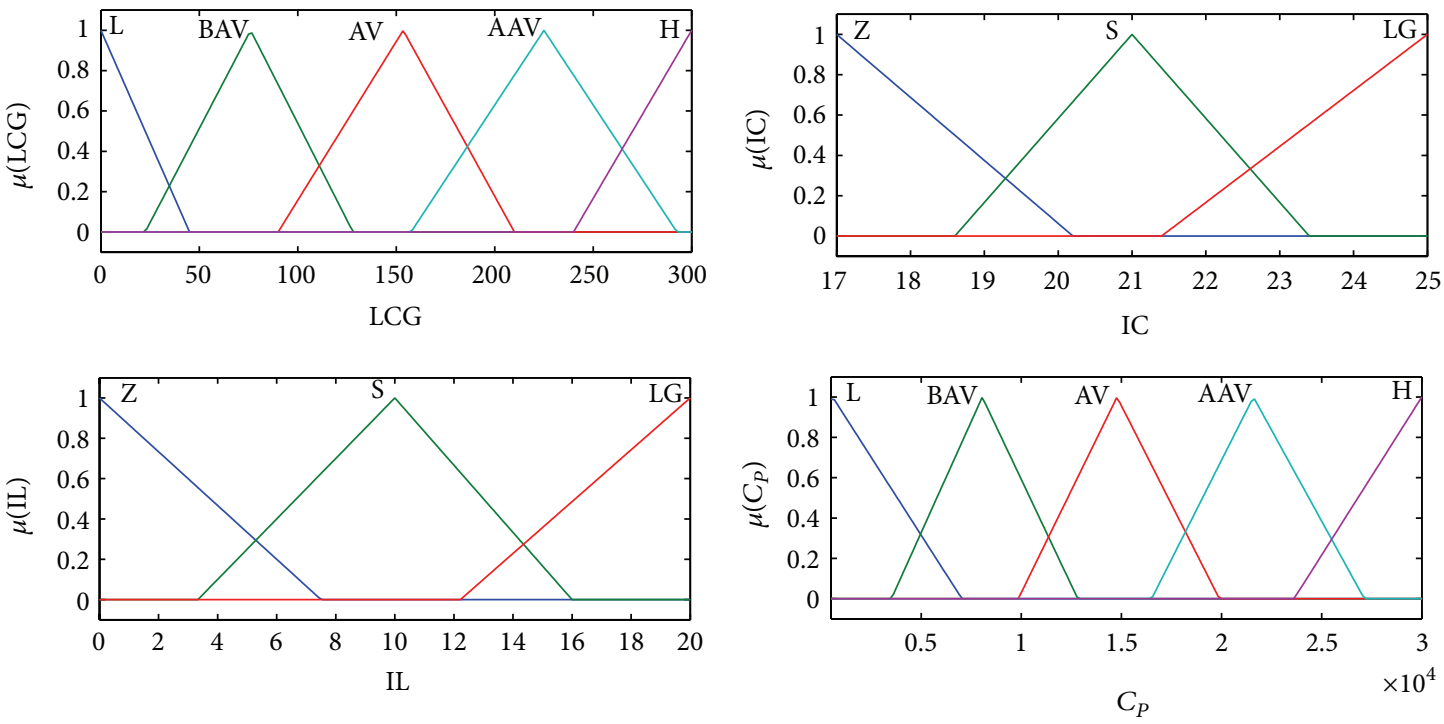

FIGURE 2: Membership functions of input/output variables.

Equations (15) represent the optimality conditions necessary to solve equation systems (1) and (5) without using inequality constraints (5) and (6). Hence, (9) can be written as follows:

$$
\lambda=\frac{\partial\left[\phi_{i}\left(P_{i h}\right)\right] / \partial P_{i h}}{\left(\partial P_{L h} / \partial P_{i h}\right)-U_{i h}} ; \quad i=1, \ldots, N_{G} ; h=1, \ldots, H .
$$

The term $\partial\left[\phi_{i}\left(P_{i h}\right)\right] / \partial P_{i h}$ represents the incremental cost (IC) of each unit $i$ and $\partial P_{L h} / \partial P_{i h}$ represents the incremental losses (IL). These terms occur as fuzzy variables associated to our strategy in order to solve the unit commitment problem.

It should be noted that the strategy is based on the integration of a fuzzy controller to optimize the cost of the production unit while ensuring proper planning of the production units. In the current formulation, the fuzzy input variables associated to the unit commitment problem are the load capacity of the generator (LCG), the incremental cost (IC), and the incremental losses (IL). The output variable is the cost of production $\left(C_{P}\right)$. The following is a brief description and explanation of the main choice of the mentioned fuzzy variables.

(i) Load capacity of generator (LCG) is considered to be fuzzy, as it is based upon the load to be served.

(ii) Incremental losses (IL) are taken to be fuzzy because the losses can lead to changes in the total production 
cost and because losses vary over the whole network architecture.

(iii) Incremental cost (IC) is taken to be fuzzy because the cost of fuel may change over the period of time and because the cost of fuel for each unit may be different.

(iv) Production cost $\left(C_{P}\right)$ of the system is treated as a fuzzy variable since it is directly proportional to the hourly load.

The fuzzy system consists of three principle components: fuzzification, fuzzy rules, and defuzzification which are described as follows [14, 33].

3.2.1. Fuzzification. Three inputs are considered, load capacity of generator (LCG), incremental losses (IL), and incremental cost (IC) and the output vector is represented by the amount of the production cost $\left(C_{P}\right)$. The triangular membership functions are considered for the fuzzification of the input variables. These last ones are presented in five fuzzy sets of linguistic values for the load capacity generator, low $(\mathrm{L})$, below average (BAV), average (AV), above average $(\mathrm{AAV})$, and high $(\mathrm{H})$. For the incremental losses (IL) and the incremental cost (IC) three fuzzy sets of linguistic values are considered, zero (Z), small (S), and large (LG). However, the output variable $\left(C_{P}\right)$ is presented in five fuzzy sets of linguistic values: low (L), below average (BAV), average (AV), above average (AAV), and high $(\mathrm{H})$ with associated triangular membership functions, as shown in Figure 2.

3.2.2. Fuzzy Rules. The Mamdani-type fuzzy rules are used to formulate the conditional statements that comprise fuzzy logic. The fuzzy rules are designed to optimize the production cost through a proper assessment of the variables LCG, IL, and IC. According to the fuzzy sets of linguistic value related to each input variable, 45 rules $(5 \times 3 \times 3=45$ rules $)$ are designed as shown in Table 1. Each rule represents a mapping from the input space to the output space.

Based on the aforementioned fuzzy sets, membership functions are selected for each fuzzy input and the fuzzy output variables. For our case study, a triangular form is used to illustrate the considered membership functions. Once the membership functions are set, the input variables are then linked to the output variable by if-then rules as shown in Figure 3.

3.2.3. Defuzzification. Moreover, once fuzzy rules are defined, the results must be defuzzified using a defuzzification method in order to achieve exact values in the desired margins. The defuzzification method used in our strategy consists of determining the abscissa of the gravity center (CDG) surface swept by the fuzzy inferences (17):

$$
\text { Production Cost }=\frac{\int_{-1}^{1} C_{P} \cdot \mu\left(C_{P}\right) \cdot d C_{P}}{\int_{-1}^{1} \mu\left(C_{P}\right) \cdot d C_{P}},
$$

with $\mu\left(C_{P}\right)$ being the membership degree of the production cost vector.
TABLE 1: Fuzzy rules relating input/output fuzzy variables.

\begin{tabular}{|c|c|c|c|c|}
\hline Rule & LCG & IC & IL & $C_{P}$ \\
\hline 1 & $\mathrm{~L}$ & $\mathrm{~L}$ & $\mathrm{Z}$ & $\mathrm{L}$ \\
\hline 2 & $\mathrm{~L}$ & $\mathrm{~L}$ & S & $\mathrm{L}$ \\
\hline 3 & $\mathrm{~L}$ & $\mathrm{~L}$ & LG & $\mathrm{L}$ \\
\hline 4 & $\mathrm{~L}$ & $\mathrm{M}$ & $\mathrm{Z}$ & $\mathrm{L}$ \\
\hline 5 & $\mathrm{~L}$ & $\mathrm{M}$ & $\mathrm{S}$ & $\mathrm{L}$ \\
\hline 6 & $\mathrm{~L}$ & $\mathrm{M}$ & LG & $\mathrm{L}$ \\
\hline 7 & $\mathrm{~L}$ & LG & $\mathrm{Z}$ & $\mathrm{L}$ \\
\hline 8 & $\mathrm{~L}$ & LG & $S$ & $\mathrm{~L}$ \\
\hline 9 & $\mathrm{~L}$ & LG & LG & $\mathrm{L}$ \\
\hline 10 & BAV & $\mathrm{L}$ & $\mathrm{Z}$ & BAV \\
\hline 11 & BAV & $\mathrm{L}$ & $S$ & BAV \\
\hline 12 & BAV & $\mathrm{L}$ & LG & BAV \\
\hline 13 & BAV & $\mathrm{M}$ & $\mathrm{Z}$ & BAV \\
\hline 14 & BAV & $\mathrm{M}$ & $S$ & BAV \\
\hline 15 & BAV & $\mathrm{M}$ & LG & BAV \\
\hline 16 & BAV & LG & $\mathrm{Z}$ & BAV \\
\hline 17 & BAV & LG & S & BAV \\
\hline 18 & BAV & LG & LG & BAV \\
\hline 19 & $\mathrm{AV}$ & $\mathrm{L}$ & $\mathrm{Z}$ & AV \\
\hline 20 & $\mathrm{AV}$ & $\mathrm{L}$ & $S$ & $\mathrm{AV}$ \\
\hline 21 & $\mathrm{AV}$ & $\mathrm{L}$ & LG & $\mathrm{AV}$ \\
\hline 22 & $\mathrm{AV}$ & $\mathrm{M}$ & $\mathrm{Z}$ & $\mathrm{AV}$ \\
\hline 23 & $\mathrm{AV}$ & $\mathrm{M}$ & $S$ & $\mathrm{AV}$ \\
\hline 24 & $\mathrm{AV}$ & $\mathrm{M}$ & LG & AV \\
\hline 25 & $\mathrm{AV}$ & LG & $\mathrm{Z}$ & AV \\
\hline 26 & $\mathrm{AV}$ & LG & $S$ & $\mathrm{AV}$ \\
\hline 27 & $\mathrm{AV}$ & LG & LG & $\mathrm{AV}$ \\
\hline 28 & AAV & $\mathrm{L}$ & $\mathrm{Z}$ & AAV \\
\hline 29 & AAV & $\mathrm{L}$ & $\mathrm{S}$ & AAV \\
\hline 30 & AAV & $\mathrm{L}$ & LG & AAV \\
\hline 31 & AAV & $\mathrm{M}$ & $\mathrm{Z}$ & AAV \\
\hline 32 & AAV & $\mathrm{M}$ & $S$ & AAV \\
\hline 33 & AAV & $\mathrm{M}$ & LG & AAV \\
\hline 34 & AAV & LG & $\mathrm{Z}$ & AAV \\
\hline 35 & AAV & LG & S & AAV \\
\hline 36 & AAV & LG & LG & AAV \\
\hline 37 & $\mathrm{H}$ & $\mathrm{L}$ & $\mathrm{Z}$ & $\mathrm{H}$ \\
\hline 38 & $\mathrm{H}$ & $\mathrm{L}$ & $S$ & $\mathrm{H}$ \\
\hline 39 & $\mathrm{H}$ & $\mathrm{L}$ & LG & $\mathrm{H}$ \\
\hline 40 & $\mathrm{H}$ & $\mathrm{M}$ & $\mathrm{Z}$ & $\mathrm{H}$ \\
\hline 41 & $\mathrm{H}$ & $\mathrm{M}$ & $\mathrm{S}$ & $\mathrm{H}$ \\
\hline 42 & $\mathrm{H}$ & $\mathrm{M}$ & LG & $\mathrm{H}$ \\
\hline 43 & $\mathrm{H}$ & LG & $\mathrm{Z}$ & $\mathrm{H}$ \\
\hline 44 & $\mathrm{H}$ & LG & S & $\mathrm{H}$ \\
\hline 45 & $\mathrm{H}$ & LG & LG & $\mathrm{H}$ \\
\hline
\end{tabular}

Hence, to minimize the objective function (1), we entrusted to the integrated fuzzy logic approach the processing of three inputs (LCG, IC, and IL). The first input is materialized by the load capacity of generator, the second is the incremental cost, and the third is the incremental losses. The fuzzy logic approach deduces the fuzzy inferences according to imposed conditions' (45 rules) and then the fuzzy logic process applies a method of defuzzification to deduce a nonfuzzy vector of command which corresponds to 


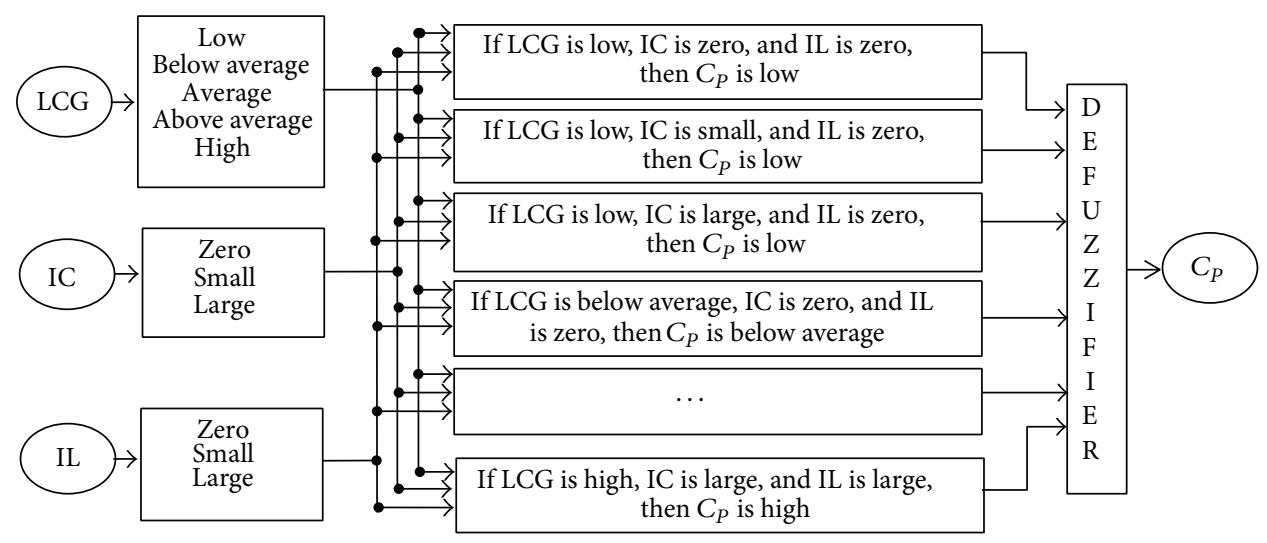

FIgURE 3: Configuration of the fuzzy logic system.

the optimal production $\operatorname{cost} C_{P}$ of the five units. The method used in order to evaluate this vector consists of determining the $X$-coordinate of the centre of gravity of the surface swept by the fuzzy deductions (17). The most remarkable advantage of this strategy is not only minimizing the production cost $C_{P}$ but also integrating in this vector the on/off states of each production unit $U_{i}$.

3.3. Gradient-Genetic Algorithm Method. The purpose of this strategy is to validate an approach to apprehend the whole problem by combining an economic model with a model having operational constraints. To achieve this objective, the approach is to combine a classical gradient method with a metaheuristic method, genetic algorithm, well suited to take into account new constraints. Minimizing the objective function (1) is equivalent to minimizing the Lagrangian function (9)

Therefore, the solution in the unit commitment problem is represented by a binary matrix $U$ of dimension $\left(l \times N_{g}\right)$. The proposed method for coding is a mix of binary and decimal numbers. Each column vector in the solution matrix (which is the operation schedule of one unit) of length $l$ is converted to its equivalent decimal number. The solution matrix is then converted into one row vector (chromosome) of $N_{g}$ decimal numbers $\left(U_{l}, U_{2}, \ldots, U_{n}\right)$; each variable represents the schedule of one unit. The numbers $U_{l}, U_{2}, \ldots, U_{n}$ are integers ranging from 0 to $\left(2^{N_{g}}-1\right)$. Accordingly, a population of size (POP) is randomly generated in a matrix $\left(N_{\mathrm{POP}} \times\right.$ $N_{g}$ ). In one individual's population, only the strongest, or in other words the best suited to the natural environment, survive and can give offspring. In each evolution stage, the genetic operators (selection, crossover, and mutation) operate based on the data structures in order to allow each individual to sweep the solutions horizon and to distinguish the global optimum among the local optima [22, 35, 36]. The best solution $\left(P_{i h}, U_{i h}\right)$ given by the genetic algorithm process is saved in one vector $\gamma_{k}$ in the gradient method in order to obtain better solution $\left(P_{i h}, U_{i h}\right)$ leading to the minimum production cost. Indeed, with this process, we have reduced in one side the search space and therefore reduced the computation time and have driven, in the other side, the gradient method to perform the specific search in a space containing the best solutions. The process of the gradient method is carried out through the research of the descent direction of the greatest slope corresponding to the minimum production cost. Indeed, we have

$$
\gamma_{k+1}=\gamma_{k}+d_{k} \cdot \xi_{k}
$$

The vectors $\gamma_{k+1}, d_{k}, \xi_{k}$ are defined by the following equations system:

$$
\begin{gathered}
\gamma_{k+1}=\left[\begin{array}{c}
P_{i h} \\
U_{i h} \\
\lambda_{i}
\end{array}\right], \\
\xi_{k}=\left[\begin{array}{c}
\frac{\partial\left(\sum_{i=1}^{N_{g}} \sum_{h=1}^{H}\left[\phi_{i}\left(P_{i h}\right)+\mathrm{ST}_{i}\left(1-U_{i(h-1)}\right)\right] U_{i h}+\lambda_{i} \cdot\left(P_{d}-\sum_{i=1}^{N_{g}} P_{i} U_{i h}\right)\right)}{\partial P_{i h}} \\
\frac{\partial\left(\sum _ { i = 1 } ^ { N _ { g } } \sum _ { h = 1 } ^ { H } \left[\phi_{i}\left(P_{i h}\right)+\mathrm{ST}_{i}\left(1-U_{i(h-1)}^{N_{g}} \sum_{h=1}^{H}\left[\phi_{i}\left(P_{i h}\right)+\mathrm{ST}_{i}\left(1-U_{i(h-1)}\right)\right] U_{i h} \cdot\left(P_{d}-\sum_{i=1}^{N_{g}} P_{i} U_{i h}\right)\right)\right.\right.}{\left.\partial X_{i h} \cdot\left(P_{d}-\sum_{i=1}^{N_{g}} P_{i} U_{i h}\right)\right)}
\end{array}\right], \\
d_{k}=\frac{\xi_{k}^{t} \cdot \xi_{k}}{\xi_{k} \cdot\left(A \cdot \xi_{k}\right)},
\end{gathered}
$$


where the Hessian matrix $A$ is defined by

$A$

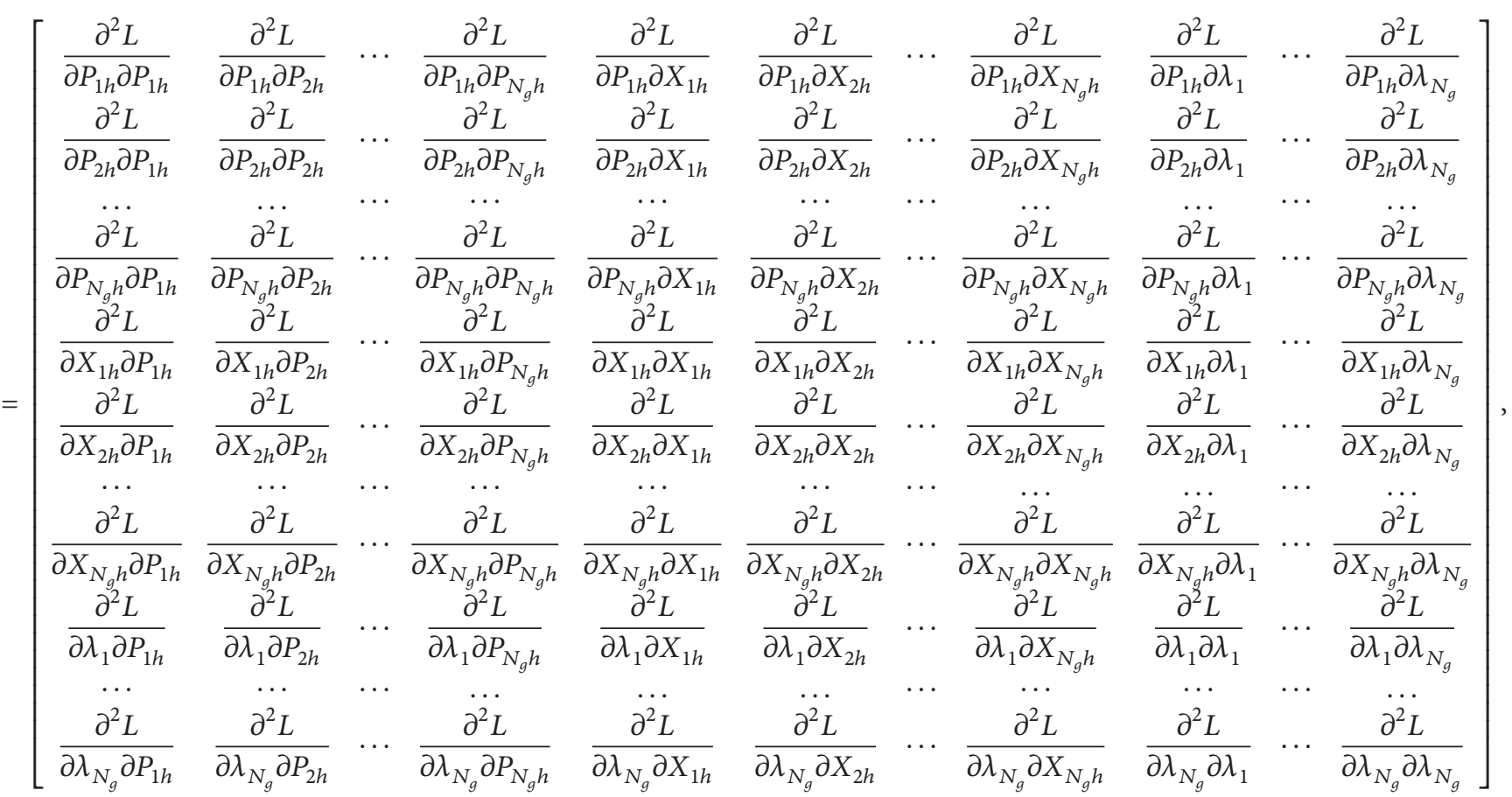

where $\xi_{k}$ presents the gradient vector indicating the descent direction to the global minimum, $d_{k}$ presents the calculation step, and $A$ presents the Hessian matrix defined by the partial derivatives of the production function relative to the generated powers and to the various on/off states of each production unit.

The proposed strategy helps not only to search effective solutions corresponding to a minimum production cost but also to proceed through an acceleration evoked by the second derivatives of the Hessian matrix so as to reach the optimal solution as quickly as possible.

The process of solving the unit commitment problem by gradient-genetic algorithm method is performed according to Figure 4.

The proposed hybrid gradient-genetic algorithm strategy differs from other evolutionary computing techniques in providing an acceptable solution within a relatively short time and is likely to lead the search towards the most promising solution area. A step-by-step gradient-genetic algorithm for the UC problem is outlined as follows.

Step 1. Read in system data for each unit.

Step 2. Initialize generation to 1 .

Step 3. Sort the fitness function $F$ value for the initial population according to (10).
Step 4. Evaluate the fitness function for the initial population $\left[\begin{array}{ll}U_{i h}^{0} & P_{i h}^{0}\end{array}\right]$.

Step 5. Check the total number of generations.

Step 6. Perform selection, probability of crossover $C_{r}$, and probability of mutation $M_{P}$ according to (12), (13), and (14),

Step 7. Evaluate the fitness function $F\left(U_{i h}, P_{i h}\right)$ for the mutated individuals.

Step 8. Compare the objective function, $F_{T}\left(P_{i h}, U_{i h}\right)(1)$, of the current individuals with the objective function of the best individuals and save individuals having the minimum objective function.

Step 9. If the current generation number reaches the predetermined maximum generation number, the search procedure is stopped; otherwise go to Step 6.

Step 10. Save the best solutions in one vector $\gamma_{k}$.

Step 11. Calculate initial parameters $\xi_{0}, d_{0}$, and $A$.

Step 12. Check the convergence criterion $\gamma_{k+1}-\gamma_{k}<\varepsilon$.

Step 13. Calculate $d_{k}$ and $\gamma_{k+1}$. 


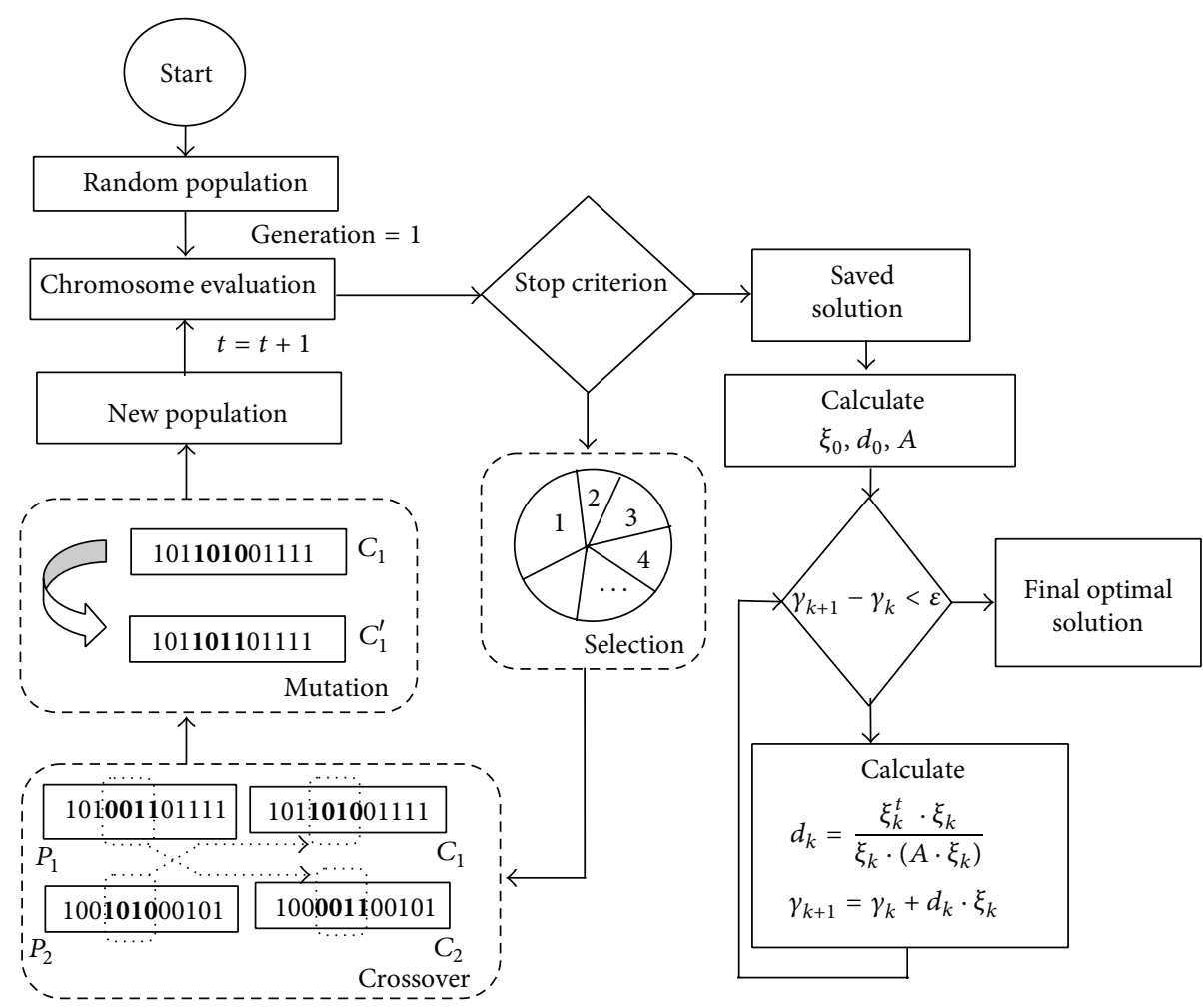

FIGURE 4: Flowchart of solving the unit commitment problem via gradient-genetic algorithm method.

Step 14. Check the convergence criterion. If $\gamma_{k+1}-\gamma_{k}<\varepsilon$, go to Step 13; else save the final solution corresponding to the unit commitment scheduling $U_{i h}$ and the generated power $P_{i h}$ for each unit $i$ and then calculate the corresponding production cost.

\section{Simulations and Results}

In order to test the performance of the optimization proposed strategies, strategies were simulated on MATLAB environment implemented on computer having the following characteristics: Core 2 Duo CPU $2.53 \mathrm{GHz}$ and 4 GB RAM. The three strategies have been applied to IEEE electrical network 14 buses [37-40], having 5 generators, over a period of 24 hours. The strategies are occurring at $t=40 \mathrm{sec}$ and the scheduling of the on/off states and the amount of generated power by each production unit is performed for each 3 hours.

The characteristics of the different production units are given in Table 2. The genetic algorithm parameters are taken as follows: crossover probability $=0.6$, mutation probability $=0.02$, population size $=40$, and maximum number of generations $=300[20,22,41]$.

In this paper, we considered 8 successive periods in order to establish the temporal evolution of the power demand, Table 3. Each period lasts for 3 hours; hence, the total period is about 24 hours.

Figure 5 illustrates the total production cost of various optimization methods for solving the unit commitment problem. Compared to the algorithms of Wei et al. [42] and C. H. Cai and Y. Y. Cai [43], we find that these optimization methods present high performance since they improved to win in the production cost.

It is clear that, through the comparison of production costs using the fuzzy logic by that one obtained using the genetic algorithm method, Table 4 , the fuzzy approach was reliable and enabled to get a gain of $1 \%$ of the total cost. However, the strategy based on the use of the gradient-genetic algorithm method was the most effective and presented high performances not only in the production cost but also in the ability of convergence to the global optimum.

Compared to other algorithms as artificial bee colony (ABC) method and particle swarm optimization (PSO) [44], it is inferred that genetic algorithm, fuzzy logic, and gradientgenetic algorithm have the best computation time. Therefore, the computation time of the unit commitment resolution through artificial bee colony is about $40.74 \mathrm{sec}$ and, through the particle swarm optimization, the computation time is equal to $49.03 \mathrm{sec}$ [44], whereas, with the proposed strategies, the computation time is highly reduced. It is equal to $10.21 \mathrm{sec}$ for genetic algorithm strategy and $12.57 \mathrm{sec}$ for the hybrid gradient-genetic algorithm strategy and the computation time is about $7.34 \mathrm{sec}$ for the fuzzy logic approach. Therefore, it is noted that the strategy based on the use of fuzzy logic method is more efficient than the other two algorithms in terms of computation time.

Table 5 shows the organization of the on/off states of the production units of the various optimization strategies. Thanks to the hybrid optimization method, we were able to organize the on/off statements of the various production units through an estimation of the amount of load required 
TABLE 2: Characteristics of production units.

\begin{tabular}{lcccccccccc}
\hline Unit & $P_{\max }(\mathrm{MW})$ & $P_{\min }(\mathrm{MW})$ & $a$ & $b$ & $c$ & $\mathrm{Up}$ & Down & Hot start cost $(\$)$ & Cold start cost (\$) & Cold start (h) \\
\hline 1 & 582 & 110 & 379.2 & 30.36 & 0.0756 & 8 & 8 & 4500 & 9000 & 340 \\
2 & 55 & 15 & 606.6 & 27.3 & 0.2274 & 3 & 3 & 170 & 170 & 340 \\
3 & 53 & 10 & 454.8 & 22.74 & 0.2274 & 3 & 3 & 30 & 60 & 2 \\
4 & 23 & 8 & 151.8 & 22.5 & 0.1518 & 1 & 1 & 30 & 60 & 0 \\
5 & 23 & 8 & 303.6 & 22.74 & 0.1518 & 1 & 1 & & 0 \\
\hline
\end{tabular}

$P_{\max }, P_{\min }:$ minimum and maximum power produced by each generator.

Up: continuously minimum up-time of unit $i$.

Down: continuously minimum down-time of unit $i$.

$a, b$, and $c$ : cost function parameters of unit $i$.

Cold start cost (\$): cold start cost of unit $i$.

Hot start cost (\$): hot start cost of unit $i$.

Cold start (h): cold start time of unit $i$.

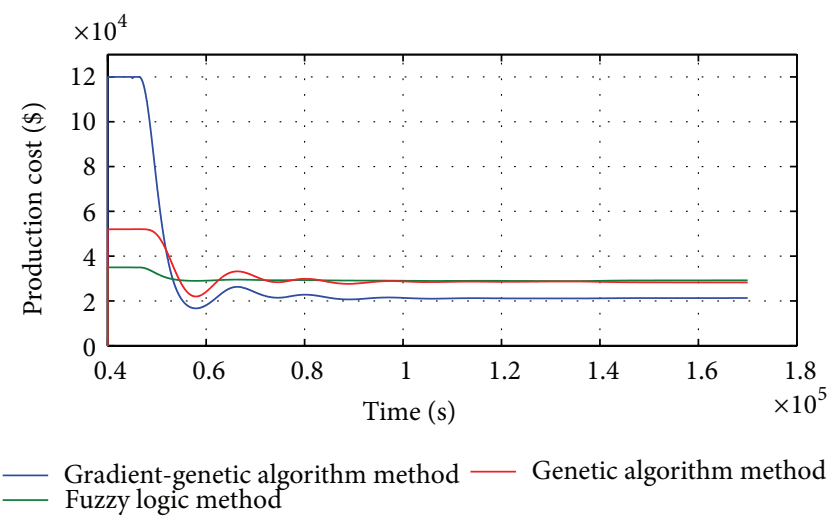

FIGURE 5: Total production cost of various optimization methods.

TABLE 3: Amount of the power demand.

\begin{tabular}{lcccccccc}
\hline Hour & 3 & 6 & 9 & 12 & 15 & 18 & 21 & 24 \\
\hline Demand (MW) & 259 & 200 & 300 & 450 & 527 & 610 & 480 & 320 \\
\hline
\end{tabular}

TABLE 4: Comparison between the optimization methods.

\begin{tabular}{lccc}
\hline & $\begin{array}{c}\text { Genetic } \\
\text { algorithm }\end{array}$ & Fuzzy logic & $\begin{array}{c}\text { Gradient-genetic } \\
\text { algorithm }\end{array}$ \\
\hline $\begin{array}{l}\text { Production } \\
\text { cost }(\$)\end{array}$ & 29457 & 29210 & 27750 \\
\hline
\end{tabular}

by the electrical grid, taking into account the allowable constraints; optimal scheduling can profit from the production cost. The superiority of the gradient-genetic algorithm method is obvious. This method operates better than the individual algorithms in terms of on/off unit commitment states scheduling and in terms of optimizing the total production cost.

In fact, based on the probability equation of such a combination planning,

$$
P_{\text {Combinaison }}=\left(2^{n}-1\right)^{m},
$$

where $n$ is the number of units and $m$ is the discretized duration. For our case study, the combining probability
$P_{\text {Combinaison }}$ is about $6.2^{35}$ combinations. This number suggests the ability of the hybrid method to choose a perfect planning, allowing guaranteeing the supply/demand balance and a minimal production cost.

Figures 6,7 , and 8 show the production scheduling of 5 units for a variable power demand during a discrete time margin (horizon time about 24 hours). Indeed, taking into account the technical constraints related to each generator (limited power, minimum down-time before restart, and minimum operating time before off state), strategies were able to get the best on/off scheduling states of the various units while optimizing the power produced by each unit within the allowable margins. Furthermore, solving the UCP by these optimization methods is considered reliable and has presented high performances especially for a problem involving identical production units, which is not the case for the application of dynamic programming method to the UCP, established in the works of Dekrajangpetch et al. [45], which could not be applied to the case of electrical network having the same characteristics of production units. However, we find that the unit commitment scheduling based on the fuzzy logic theory (Figure 6) is more promising than that one established using the genetic algorithm (Figure 7) and this can be observed on the temporal evolution of the power produced by the most powerful generator (615 MVA), which suggests the effectiveness of resolution through the fuzzy 
TABLE 5: Optimal binary combination of units operation.

\begin{tabular}{lccc}
\hline Unit & $\begin{array}{c}\text { Units operation scheduling } \\
\text { using genetic algorithm }\end{array}$ & $\begin{array}{c}\text { Units operation scheduling } \\
\text { using fuzzy logic }\end{array}$ & $\begin{array}{c}\text { Units operation scheduling using } \\
\text { gradient-genetic algorithm }\end{array}$ \\
\hline Unit 1 & 11111111 & 11111111 & 11111111 \\
Unit 2 & 00111111 & 00111111 & 00111110 \\
Unit 3 & 00111110 & 00011110 & 00111110 \\
Unit 4 & 00001110 & 00001110 & 00001110 \\
Unit 5 & 00001100 & 00001100 & 00001000 \\
\hline
\end{tabular}

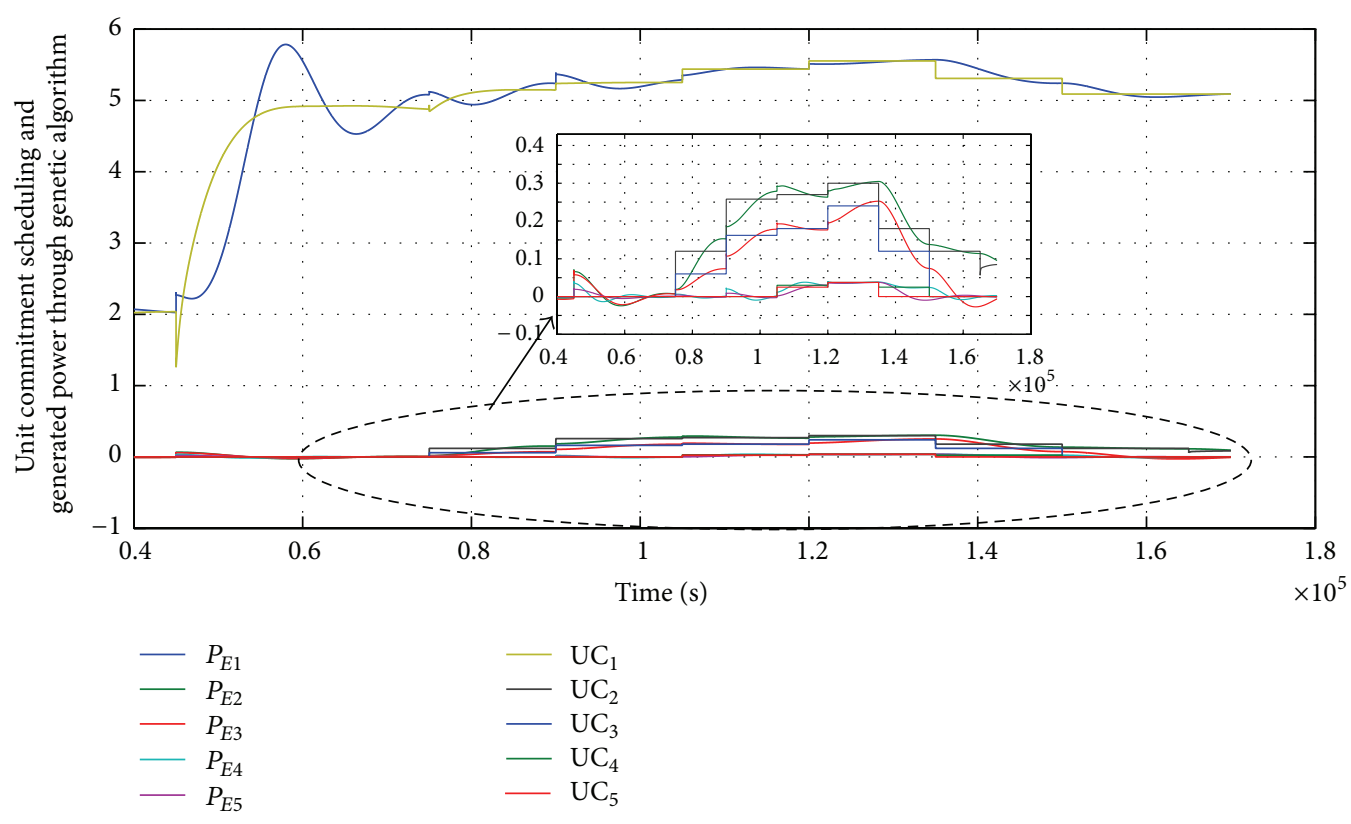

FIGURE 6: Unit commitment scheduling and generated power through genetic algorithm.

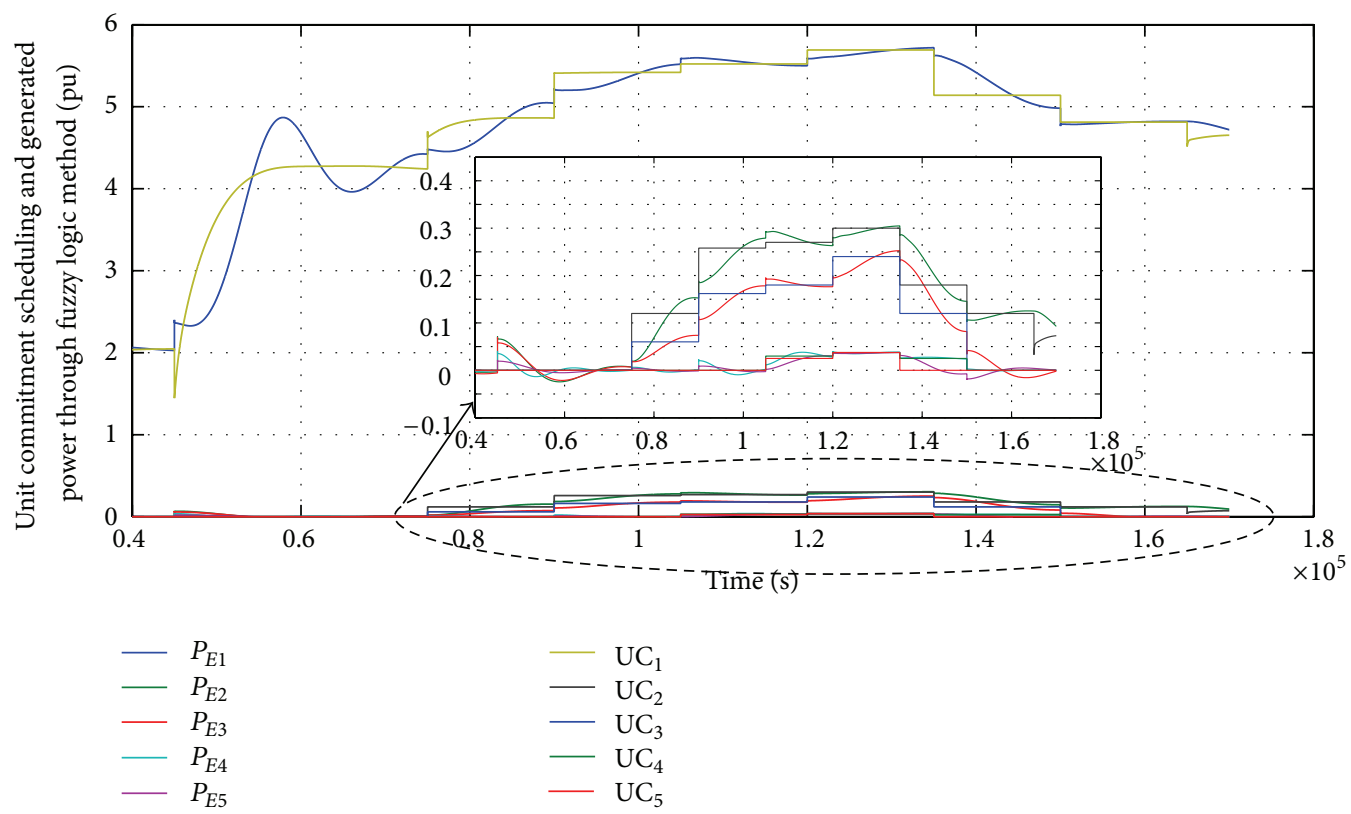

FIGURE 7: Unit commitment scheduling and generated power through fuzzy Logic. 


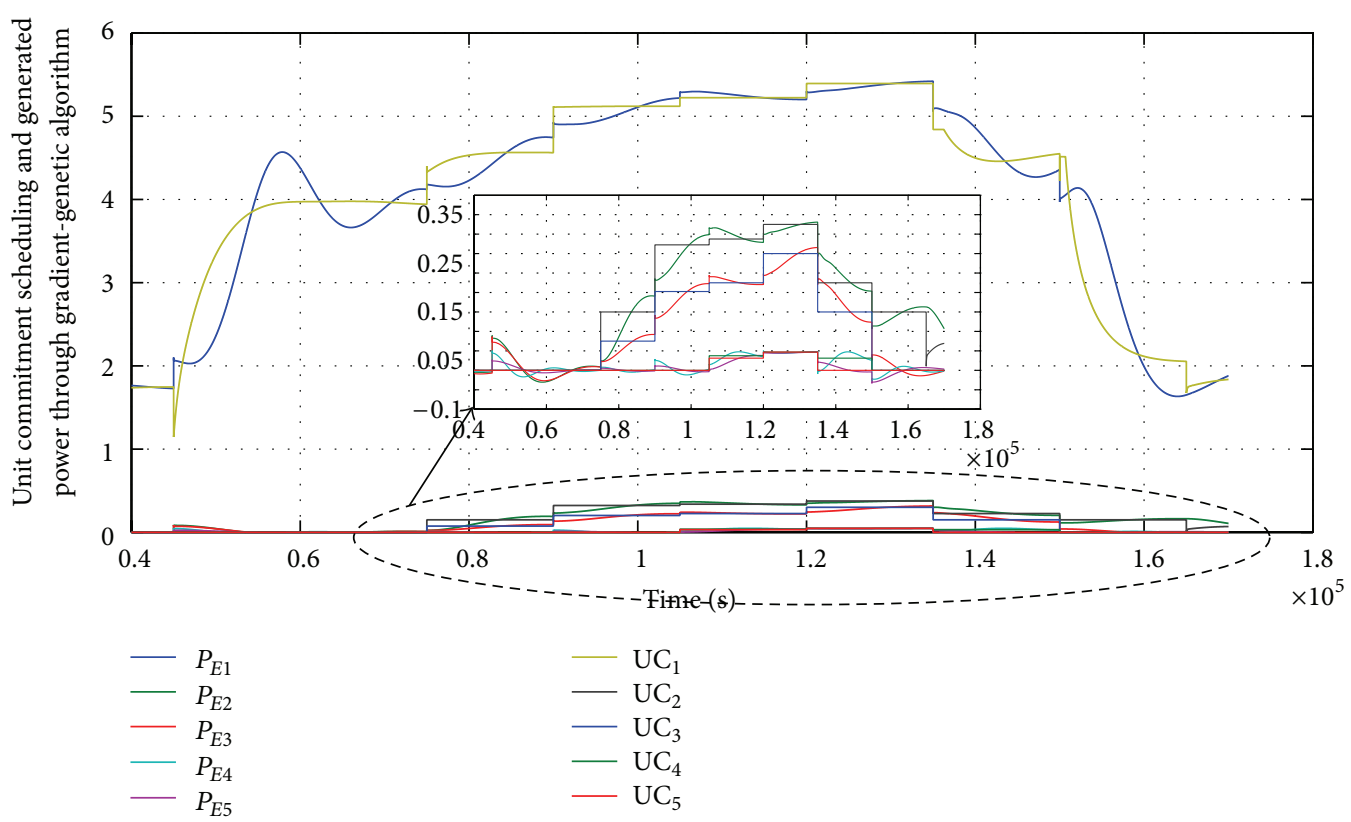

FIGURE 8: Unit commitment scheduling and generated power through gradient-genetic algorithm method.

logic approach especially in presence of systems that are difficult to model. Nevertheless, the strategy based on the use of gradient-genetic algorithm method (Figure 8) remains the most promising and could be applied to solve the UCP for systems having complicated architecture and for any number of production units. Knowing that the minimization of the production cost equation is closely related to the optimization of the generated power $P_{i h}$, the efficiency of resolutiongenetic approach gradient algorithm is guaranteed with great consideration in the limitation of the amount of produced active power by each generator per hour and in the allowable voltage levels margins for each electrical network.

The improvement of the production cost for the model based on fuzzy approach depends on the number of fuzzy rules taken in the resolution. However, increasing this number leads to increasing the horizon of solutions research which implies the increase of the execution time. Furthermore, the optimization of the production cost through genetic algorithm requires a proper selection of the GA parameters which vary from one system to another. Thus, it is difficult to reduce for both the execution time and the production cost for the mentioned methods. With regard to production cost, the proposed strategy based on gradientgenetic algorithm method is more promising. Indeed, it leads to a better combination of the production units operating states leading to an optimal production cost, while, regarding convergence speed and execution time, the approach based on fuzzy logic has presented high performances.

\section{Conclusion}

A comparative study between a strategy based on hybrid gradient-genetic algorithm method and two metaheuristic methods for solving the unit commitment problem has been the subject of this work. The simulation results showed that, in terms of execution time and convergence effectiveness, the resolution through fuzzy logic is reliable despite the fact that the production cost is relatively minimal but did not present the best production cost. Yet, the proposed strategy which combines genetic algorithm and gradient method has presented high performances in optimizing the production cost and capability of convergence to a global optimum. In addition, the hybrid strategy has ensured a proper unit commitment scheduling of the various production units throughout the optimization of the produced power. Moreover, the right choice of the initial population suggests the possibility of obtaining improvements in execution time. These factors illustrate the effectiveness of this strategy and show that it can be applied for solving the unit commitment problem of an electrical grid having complicated architecture and containing any number of production units.

\section{Conflict of Interests}

The authors declare that there is no conflict of interests regarding the publication of this paper.

\section{References}

[1] T. A. A. Victoire and A. E. Jeyakumar, "Unit commitment by a tabu-search-based hybrid-optimisation technique," IEE Proceedings-Generation, Transmission and Distribution, vol. 152, no. 4, pp. 563-574, 2005.

[2] C. C. A. Rajan and M. R. Mohan, "An evolutionary programming-based tabu search method for solving the unit commitment problem," IEEE Transactions on Power Systems, vol. 19, no. 1, pp. 577-585, 2004.

[3] S. Kharbash and W. Wang, "All-terminal network reliability optimization in fading environment via cross entropy method," 
in proceeding of the IEEE International Conference on Communications (ICC '10), pp. 1-5, Cape Town, South Africa, May 2010.

[4] W. L. Snyder Jr., H. D. Powell Jr., and J. C. Rayburn, “ Dynamic programming approach to unit commitment," IEEE Transactions on Power Systems, vol. 2, no. 2, pp. 339-348, 1987.

[5] X. Guan, P. B. Luh, H. Yan, and J. A. Amalfi, "An optimizationbased method for unit commitment," International Journal of Electrical Power and Energy Systems, vol. 14, no. 1, pp. 9-17, 1992.

[6] Z. Ouyang and S. M. Shahidehpour, "An intelligent dynamic programming for unit commitment application," IEEE Transactions on Power Systems, vol. 6, no. 3, pp. 1203-1209, 1991.

[7] A. Merlin and P. Sandrin, "A new method for unit commitment at Electricite de France," IEEE Transactions on Power Apparatus and Systems, vol. 102, no. 5, pp. 1218-1225, 1983.

[8] F. Zhuang and F. D. Galiana, "Towards a more rigorous and practical unit commitment by Lagrangian relaxation," IEEE Transactions on Power Systems, vol. 3, no. 2, pp. 763-773, 1988.

[9] J. M. Arroyo and A. J. Conejo, "Optimal response of a thermal unit to an electricity spot market," IEEE Transactions on Power Systems, vol. 15, no. 3, pp. 1098-1104, 2000.

[10] C. L. Chen and S. C. Wang, "Branch-and-bound scheduling for thermal generating units," IEEE Transactions on Energy Conversion, vol. 8, no. 2, pp. 184-189, 1993.

[11] D. C. Walters and G. B. Sheble, "Genetic algorithm solution of economic dispatch with value point loading," IEEE Transactions on Power Systems, vol. 8, no. 3, pp. 1325-1332, 1993.

[12] F. T. Lin, C. Y. Kao, and C. Hsu, "Applying the genetic approach to simulated annealing in solving some NP-hard problems," IEEE Transactions on Systems, Man and Cybernetics, vol. 23, no. 6, pp. 1752-1767, 1993.

[13] S. Kumar and V. Palanisamy, "A hybrid fuzzy dynamic programming approach to unit commitment," IE (I) Journal-EL, vol. 88, 2008.

[14] A. A. Jasser, "Solving the unit-commitment problem using fuzzy-logic," International Journal of Computer and Electrical Engineering, vol. 3, no. 6, pp. 824-829, 2011.

[15] H. M. F. AboElfotoh and L. S. Al-Sumait, "A neural approach to topological optimization of communication networks, with reliability constraints," IEEE Transactions on Reliability, vol. 50, no. 4, pp. 397-408, 2001.

[16] F. T. Lin, C. Y. Kao, and C. C. Hsu, "Applying the genetic approach to simulated annealing in solving some NP-hard problems," IEEE Transactions on Systems, Man and Cybernetics, vol. 23, no. 6, pp. 1752-1767, 1993.

[17] C. C. A. Rajan, M. R. Mohan, and K. Manivannan, "Refined simulated annealing method for solving unit commitment problem," in Proceedings of the International Joint Conference on Neural Networks (IJCNN '02), vol. 1, pp. 333-338, Honolulu, Hawaii, USA, May 2002.

[18] Ü. Başaran Filik and M. Kurban, "Solving unit commitment problem using modified subgradient method combined with simulated annealing algorithm," Mathematical Problems in Engineering, vol. 2010, Article ID 295645, 15 pages, 2010.

[19] M. Sudhakaran, P. Ajay, and D. V. Raj, "Integrating genetic algorithms and Tabu search for unit commitment problem," International Journal of Engineering of Science and Technology, vol. 2, no. 1, pp. 57-69, 2010.

[20] C.-P. Cheng, C. W. Liu, and C. C. Liu, "Unit commitment by annealing-genetic algorithm," International Journal of Electrical Power and Energy Systems, vol. 24, no. 2, pp. 149-158, 2002.
[21] C. Yingvivatanapong, Multi-area unit commitment and economic dispatch with market operation components [Ph.D. thesis], University of Texas, Arlington, Va, USA, 2006.

[22] I. G. Damousis, A. G. Bakirtzis, and P. S. Dokopoulos, "A solution to the unit-commitment problem using integer-coded genetic algorithm," IEEE Transactions on Power Systems, vol. 19, no. 2, pp. 1165-1172, 2004.

[23] K. S. Swarup and S. Yamashiro, "Unit commitment solution methodology using genetic algorithm," IEEE Transactions on Power Systems, vol. 17, no. 1, pp. 87-91, 2002.

[24] T. T. Maifeld and G. B. Sheble, "Genetic-based unit commitment algorithm," IEEE Transactions on Power Systems, vol. 11, no. 3, pp. 1359-1370, 1996.

[25] S. A. Kazarlis, A. G. Bakirtzis, and V. Petridis, "A genetic algorithm solution to the unit commitment problem," IEEE Transactions on Power Systems, vol. 11, no. 1, pp. 83-92, 1996.

[26] A. H. Mantawy, Y. L. A. Magid, and S. Z. Selim, "A simulated annealing algorithm for unit commitment," IEEE Transactions on Power Systems, vol. 13, no. 1, pp. 197-204, 1998.

[27] N. P. Padhy, "Unit commitment using hybrid models: a comparative study for dynamic programming, expert system, fuzzy system and genetic algorithms," International Journal of Electrical Power and Energy Systems, vol. 23, no. 8, pp. 827-836, 2001.

[28] U. B. Filik and M. Kurban, "Feasible modified subgradient method for solving the thermal unit commitment problem as a new approach," Mathematical Problems in Engineering, vol. 2010, Article ID 159429, 11 pages, 2010.

[29] M. U. Kurban and A. Filik, "A comparative study of three different mathematical methods for solving the unit commitment problem," Mathematical Problems in Engineering, vol. 2009, Article ID 368024, 13 pages, 2009.

[30] N. Zhang, W. Li, R. Liu, Q. Lv, and L. Sun, "A three-stage birandom program for unit commitment with wind power uncertainty," The Scientific World Journal, vol. 2014, Article ID 583157, 12 pages, 2014.

[31] M. Angelova and T. Pencheva, "Tuning genetic algorithm parameters to improve convergence time," International Journal of Chemical Engineering, vol. 2011, Article ID 646917, 7 pages, 2011.

[32] D. K. Dey, "Mathematical study of adaptive genetic algorithm (AGA) with mutation and crossover probabilities," International Journal of Advanced Computer Technology, vol. 3, no. 5, pp. 765-768, 2014.

[33] A. Y. Saber, T. Senjyu, A. Yona, and T. Funabashi, "Unit commitment computation by fuzzy adaptive particle swarm optimisation," IET Generation, Transmission \& Distribution, vol. 1, no. 3, pp. 456-465, 2007.

[34] S. Marrouchi and S. Chebbi, "New strategy based on fuzzylogic approach to solve the unit-commitment problem," in Proceedings of the International Conference on Control, Engineering Information Technology (CEIT '14), Sousse, Tunisia, March 2014.

[35] M. Sudhakaran and P. Ajay-D-Vimal-Raj, "Integrating genetic algorithms and tabu search for unit commitment problem," International Journal of Engineering, vol. 2, no. 1, pp. 57-69, 2010.

[36] S. Marrouchi and S. Chebbi, "Combined use of genetic algorithms and gradient optimization methods for unit commitment problem resolution," Wulfenia Journal, vol. 20, no. 8, pp. 357-369, 2013.

[37] R. Abbassi, S. Marrouchi, M. Ben Hessine, S. Chebbi, and H. Jouini, "Voltage control strategy of an electrical network by the integration of the UPFC compensator," International Review on Modelling and Simulations, vol. 5, no. 1, pp. 380-384, 2012. 
[38] M. B. Hessine, S. Marrouchi, S. Chebbi, H. Jouini, and R. Abbassi, "Preventive and curative strategies based on fuzzy logic used for voltage stabilization of an electrical network," International Review on Modelling and Simulations, vol. 4, no. 6, pp. 3201-3207, 2011.

[39] M. B. Hessine, H. Jouini, S. Chebbi, and S. Marrouchi, "Voltage and frequency stabilization of electrical networks by using load shedding strategy based on fuzzy logic controllers," International Review of Electrical Engineering, vol. 7, no. 5, pp. 56945704, 2012.

[40] R. Abbassi and S. Chebbi, "Energy management strategy for a grid-connected wind-solar hybrid system with battery storage: Policy for optimizing conventional energy generation," International Review of Electrical Engineering, vol. 7, no. 2, pp. 39793990, 2012.

[41] B. Zhao, C. X. Guo, B. R. Bai, and Y. J. Cao, "An improved particle swarm optimization algorithm for unit commitment," International Journal of Electrical Power and Energy Systems, vol. 28, no. 7, pp. 482-490, 2006.

[42] P. Wei, N. Li, H. Wu, Y. Zhang, X. Wang, and B. Zhu, "Daily generation scheduling based on genetic algorithm," Automation of Electric Power Systems, vol. 23, no. 10, pp. 23-27, 1999.

[43] C. H. Cai and Y. Y. Cai, "Optimization of unit commitment by genetic algorithm," Power System Technology, vol. 21, pp. 44-47, 1997.

[44] K. Chandrasekaran, S. Hemamalini, S. P. Simon, and N. P. Padhy, "Thermal unit commitment using binary/real coded artificial bee colony algorithm," Electric Power Systems Research, vol. 84, no. 1, pp. 109-119, 2012.

[45] S. Dekrajangpetch, G. B. Sheble, and A. J. Conejo, "Auction implementation problems using LaGrangian Relaxation," IEEE Transactions on Power Systems, vol. 14, no. 1, pp. 82-88, 1999. 


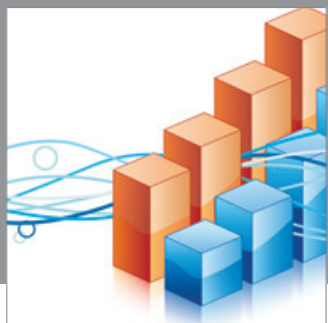

Advances in

Operations Research

mansans

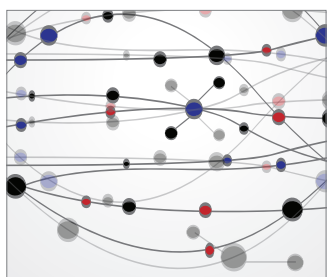

The Scientific World Journal
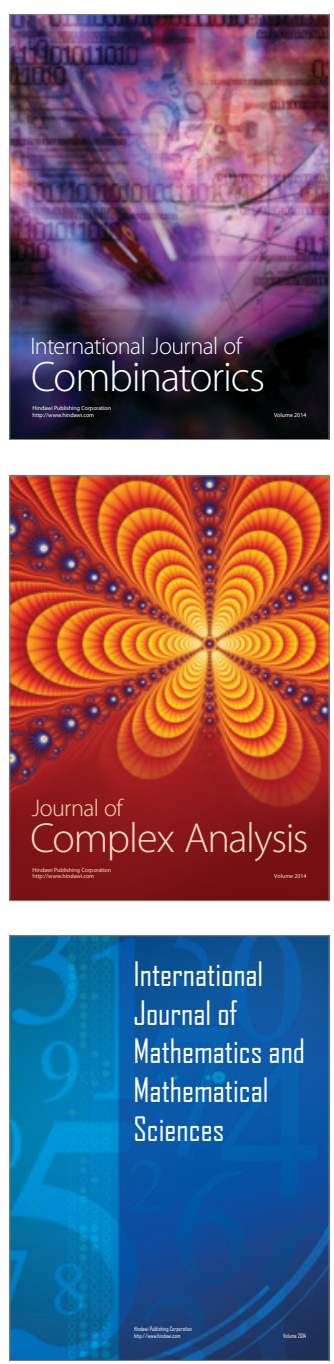
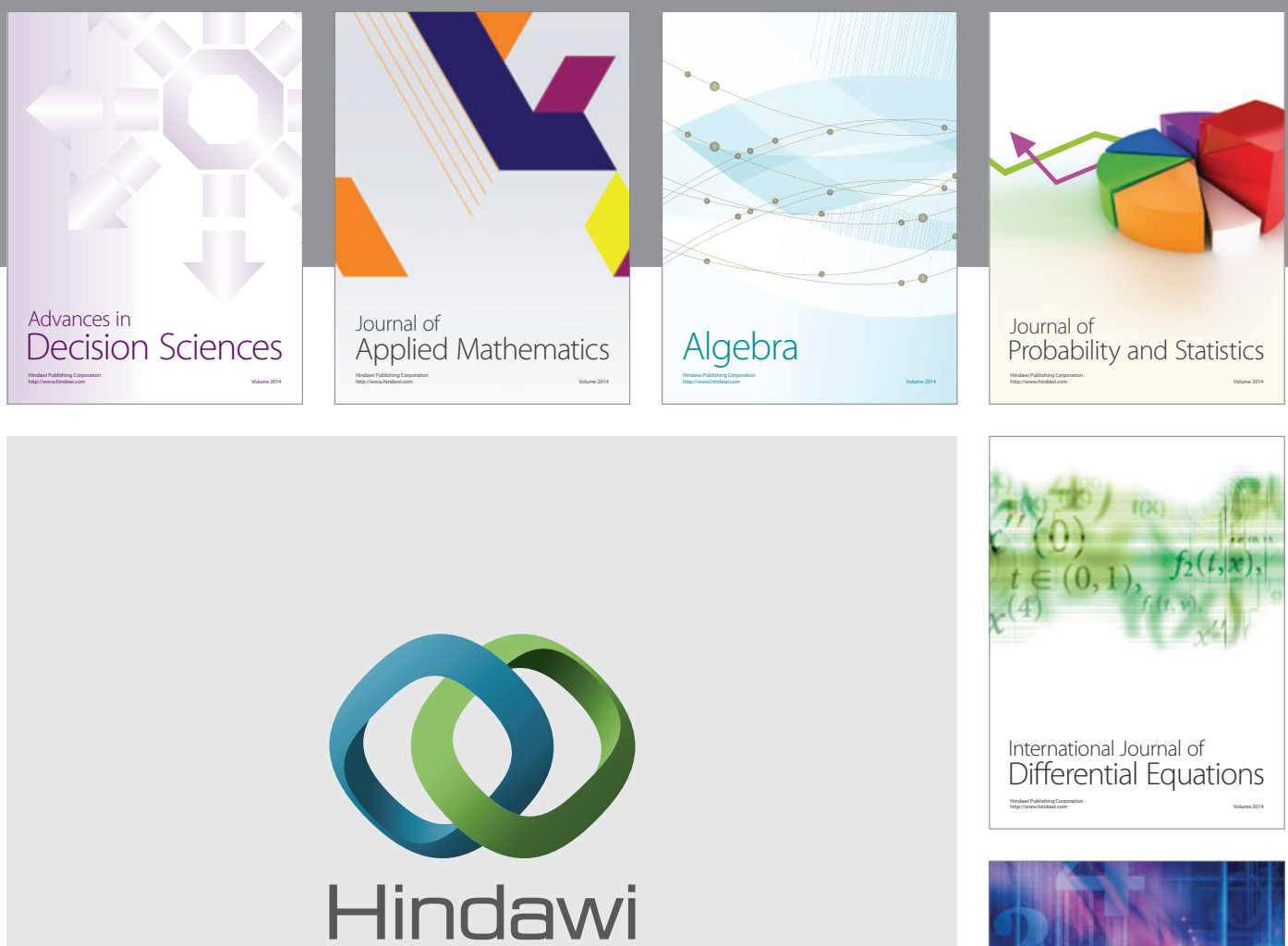

Submit your manuscripts at http://www.hindawi.com
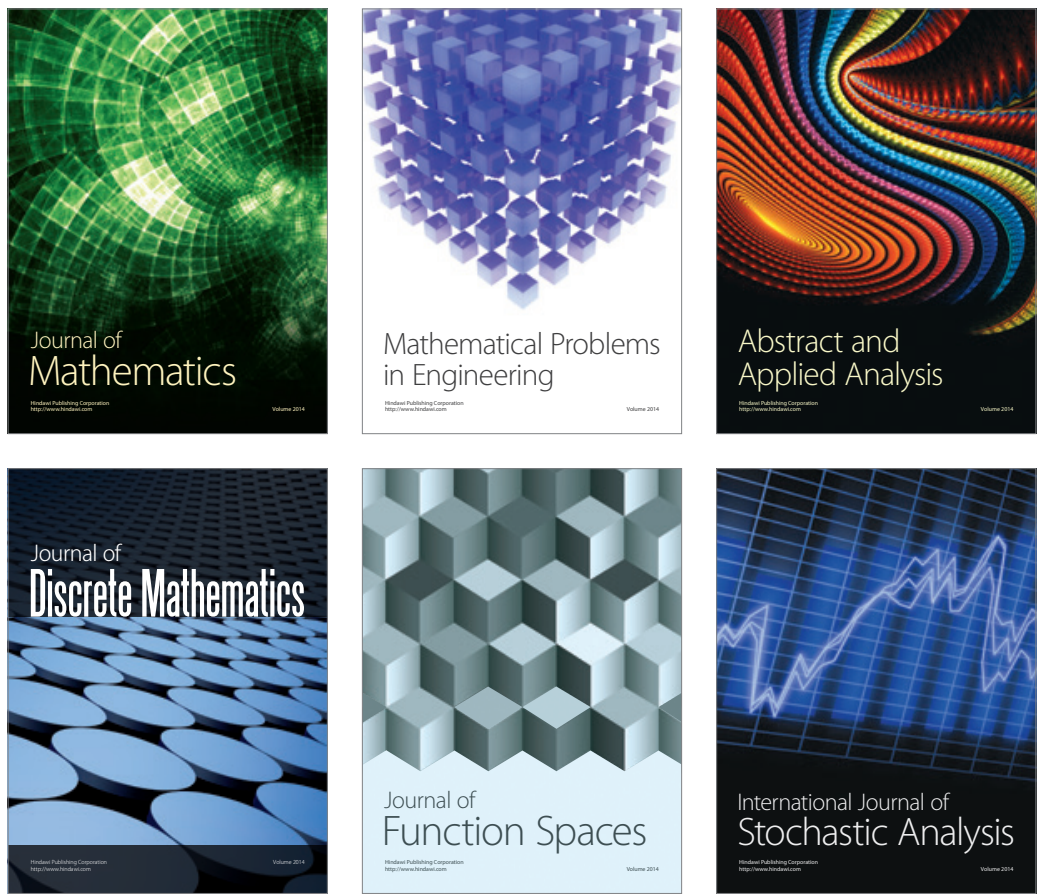

Journal of

Function Spaces

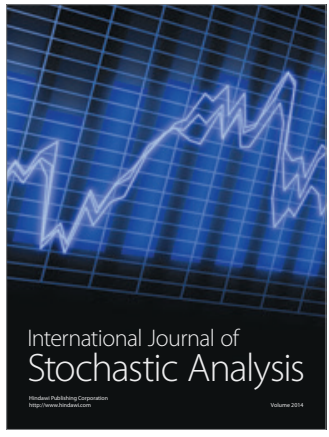

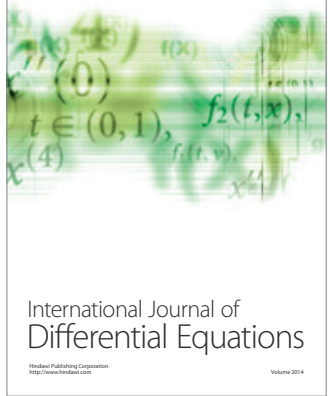
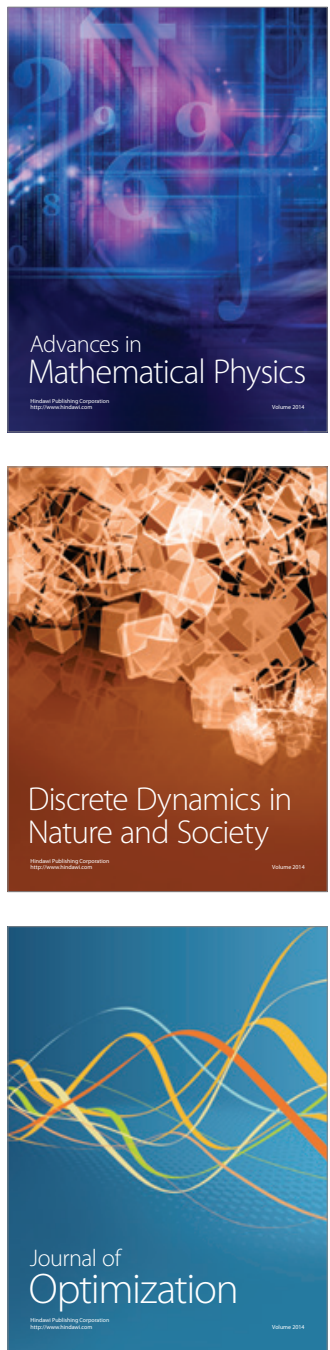